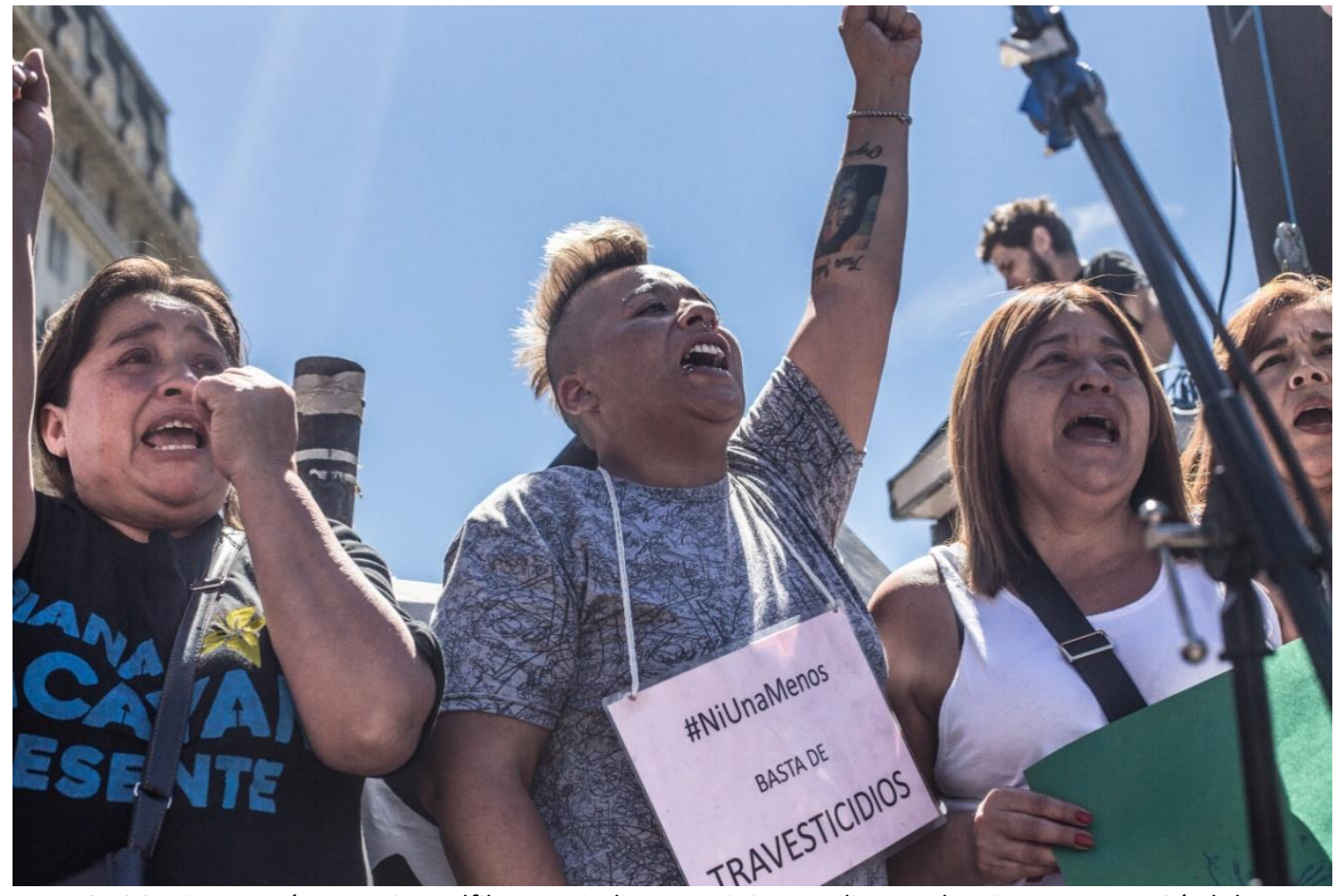

FOTOS: Irina Morán - Revista Alfilo - Periodista Feminista. Militante de Ni Una Menos Córdoba y Mujeres por un parto Respetado 


\title{
RELAÇÕES DE GÊNERO EM SALA DE AULA: COMPARTILHANDO EXPERIÊNCIAS DO PIBID INTERDISCIPLINAR DE PETROLINA
}

\author{
Janaina Guimarães da Fonseca Silva ${ }^{1}$
}

\begin{abstract}
Resumo: Levando em consideração as novas diretrizes para os cursos de licenciatura, de julho de 2015, e também, a tentativa de reação aos diversos projetos que pretendem limitar as discussões de gênero em sala de aula, nosso projeto, aqui apresentado, utilizou o PIBID-Programa de Iniciação à Docência da CAPES, para trabalhar as relações de gênero, em escolas públicas de Petrolina, no ano de 2016. O projeto foi coordenado por Janaina Guimarães e desenvolvido pelas alunas e alunos dos cursos de Licenciatura em História e Biologia da Universidade de Pernambuco, Campus Petrolina, numa perspectiva interdisciplinar. Nossa proposta teve como objetivo trabalhar a construção histórica dos conceitos de sertaneja e sertanejo, por meio das relações de gênero, focando a realidade das/os alunas/os e seu papel enquanto agentes históricos, estimulando-as/os a desenvolverem um olhar crítico sobre os estereótipos e preconceitos machistas e misóginos presentes nas práticas cotidianas. As atividades desenvolvidas ao longo do ano, bem como o material que utilizamos como base, produzido pela Ação Educativa e pelo instituto Sou da Paz, serão descritos e analisados, bem como a recepção por parte das/os licenciadas/os, tutores e estudantes do Ensino Médio à abordagem das relações de gênero em sala de aula.
\end{abstract}

Palavras chave: gênero; Interdisciplinar; educação.

\section{GENDER RELATIONS IN A CLASSROOM: SHARING EXPERIENCES OF INTERDISCIPLINARY PIBID OF PETROLINA}

\begin{abstract}
Taking into account the new guidelines for undergraduate courses of July 2015 and also the attempt to react to the various projects that intend to limit the gender discussions in the classroom, our project, presented here, used the PIBID Initiation Program The Teaching of CAPES, to work on gender relations, in public schools of Petrolina, in the year 2016. The project was coordinated by Janaina Guimarães and developed by the students of the Degree in History and Biology of the University of Pernambuco, Campus Petrolina, in an interdisciplinary perspective. Our purpose was to work on the historical construction of the concepts of sertaneja and sertanejo through gender relations, focusing the reality of the students and their role as historical agents, stimulating them to develop a critical eye on The sexist and misogynist stereotypes and prejudices present in everyday practices. The activities developed throughout the year, as well as the material we use as a base, produced by Ação Educativa and the Sou da $\mathrm{Paz}$ Institute, will be described and analyzed, as well as the reception by the graduates, tutors and students of the High School to the approach of gender relations in the classroom.
\end{abstract}

Keywords: gender; Interdisciplinary; education

\section{INTRODUÇÃO}

A introdução das discussões de gênero no Programa de Iniciação à Docência PIBID - do campus Petrolina, foi parte de uma iniciativa da coordenação de História frente a algumas práticas misóginas visualizadas entre os próprios pibidianos. Falas informais nos corredores, chacotas entre colegas e com alunas e alunos das escolas

\footnotetext{
${ }^{1}$ Janaina Guimarães da Fonseca e Silva é doutora em história pela Universidade federal de Pernambuco. Professora adjunta da Universidade de Pernambuco, campus Mata Norte em Nazaré da Mata. No Campus Petrolina, é membro permanente do Programa de Pós-graduação em Formação de Professores e Práticas Interdisciplinares (PPGFPPI). Possui graduação em História pela Universidade Federal de Pernambuco, mestrado em História pela mesma Universidade. Tem experiência na área de ensino de História e relações de gênero, atuando, principalmente, nos seguintes temas: estudos interdisciplinares, educação, gênero, mulheres. E-mail: guimaraes.janaina@gmail.com
} 
onde o programa funcionava nos levaram a questionar: que formação nós estamos dando a nossas licenciadas e a nossos licenciados? Somamos a isso o alto índice de violência contra a mulher no sertão pernambucano e a necessidade de um debate sobre as relações de gênero no ambiente escolar e redefinimos o projeto do PIBID interdisciplinar para o ano de 2016. Nosso foco foi então: por que se costuma atribuir ao sertanejo a braveza, a fúria e a grande preocupação com a honra? E se isso reflete, ainda hoje, nas relações violentas na região. Esse artigo é um relato de nossa experiência ao longo do ano de 2016, na coordenação de área do PIBID. Transformamos essa experiência em pesquisa para compreender como alunas/os, professoras/es e pibidianas/os vivenciaram e compreenderam o debate sobre as questões de gênero em sala de aula durante esse ano.

O sertanejo problematizado nas obras literárias é o mesmo sertanejo dos dias atuais? E a mulher sertaneja, sobre a qual pouco se fala? Como essas imagens foram cristalizadas no imaginário nacional? Como desconstruí-las? E como as obras literárias podem ser abordadas para compreender a construção dessas imagens? Essas são algumas das questões que construímos ao redirecionar o projeto em curso desde $2014 \mathrm{e}$ que, em 2016, envolveu alunas e alunos bolsistas dos cursos de licenciatura em História e Biologia da Universidade de Pernambuco.

\section{DESENVOLVIMENTO}

Divididos em duas escolas, a Escola de Aplicação Vande de Souza e a Escola Otacílio Nunes, ambas em Petrolina, as 10 alunas e 9 alunos do PIBID interdisciplinar, sob nossa coordenação, formaram pequenos grupos e elaboraram um projeto de intervenção, cujo objetivo principal foi despertar alunas e alunos do Ensino Médio para as desigualdades de gênero e aplicar recursos didáticos previamente elaborados nas escolas.

As reuniões para elaboração dos projetos de cada grupo ocorreram em Janeiro de 2016 e foram precedidas por um minicurso intitulado "Por que não falar de gênero?", cujos objetivos era discutir os empecilhos à abordagem das relações de gênero na educação e a importância dessas discussões para a construção de uma escola plural, em consonância com as demandas atuais da sociedade. Vale ressaltar que a maioria dos bolsistas já vinha no projeto desde 2014, tendo, portanto, conhecimento do funcionamento do programa. 
As/os pibidianas/os tiveram, ao longo do desenvolvimento das atividades, reuniões semanais de atualização teórica e de orientação. As atividades foram acompanhadas, também, pelos professores tutores das duas escolas, dois homens de 30 e 40 anos, que nunca tinham trabalhado com a temática de gênero, nem com o tema transversal Orientação Sexual. Eles também participaram do minicurso e das discussões sobre os conceitos de gênero e sertão.

Nossa compreensão de gênero tem por base a definição de Scott (1995) como sendo construções sociais e eminentemente relações de poder. Concorrem para a formulação do conceito de gênero não só os caracteres anatômicos distintivos entre os sexos, mas também um conjunto de representações sociais relativas a estes, consubstanciadas em conceitos e símbolos que, dentre outros propósitos, pretendem delimitar o campo de atuação e os papéis sociais pertinentes ao masculino e ao feminino. Tais representações e símbolos não só circunscrevem os sexos a campos de atuação mais ou menos bem delimitados, como lhes confere certa aura de fixidez, de "naturalidade", de imobilidade histórica no desempenho de tais papéis sociais, que seriam, em última análise, constructos sociais e culturais, ao invés de algo dado pela natureza. Os estudos de Foucault (1988) foram bastante precisos em indicar a genealogia desses mecanismos de dominação (particularmente no cenário de emergência da modernidade), situando, na raiz do problema, os saberes e discursos que sustentavam tais mecanismos e tornavam os corpos "dóceis", disciplinados e regulados.

As atividades dos projetos foram variadas, apresentação de documentários; pesquisa sobre o papel das mulheres em outras culturas; relatos de casos contemporâneos e concretos comparados às obras literárias; leitura teatralizada de trechos da obra Vozes do Mato, entre outras. Após três meses de desenvolvimento das atividades em sala, as/os pibidianas/os responderam a um primeiro questionário sobre a experiência, a receptividade de alunas/os e tutores. Também filmamos vídeos registrando as impressões acerca dos impactos das atividades. No segundo momento do projeto, dedicamo-nos à aplicação de oficinas já desenvolvidas por Associações e Institutos que trabalham com Gênero e Educação, como o Sou da Paz e o Gênero e Educação, que disponibilizam online seu material. Nossa inquietação era saber como esses materiais, pensados previamente, se adaptariam a nossa realidade de tempo, de recursos e de contexto de informações.

A ausência gritante do termo gênero no PNE de 2014, reelaborado à revelia do proposto pelas educadoras e educadores do País, ainda que chocante, responde à lógica de Momento: diálogos em educação, E-ISSN 2316-3100, v. 28, n. 3, p. 303-315, set./dez, 2018. 
deslegitimação dos processos coletivos, como já ocorreu em 1996, quando da elaboração da Lei de Diretrizes e Bases da Educação (LDB). O então projeto elaborado pelas/os educadoras/es mobilizadas/os no Fórum Nacional em Defesa da Escola Pública (1990) foi substituído por um projeto elaborado e apresentado pelo então senador Darcy Ribeiro, de clara influência neoliberal, cuja aprovação foi amplamente defendida pelo Presidente Fernando Henrique Cardoso, e modificou várias das demandas oriundas do projeto já elaborado por docentes. Entre essas modificações, destaca-se a falta de limitação do número de alunas e alunos em sala; a garantia da educação de jovens e adultos em todos os níveis, deixando apenas o Fundamental; no Ensino Médio, oferece apenas o supletivo e EAD; não propõe a organização de estudantes e não traz um piso salarial nacional, mas, sim, a possibilidade de pisos salariais e municiais (Vianna, 2011: 145).

O termo gênero também não está presente nos objetivos gerais do Plano Nacional de educação de 2001, constando, sim, em tópicos específicos. (Vianna, 2011:155). Compreendemos, então, que o projeto neoliberal que pauta a educação brasileira há anos tem suas demandas intensificadas no governo da presidente Dilma Houself, em resposta às melhoras provocadas pelas políticas públicas implementadas desde 2003 pelo governo Lula, que se chocam com as bases desse projeto.

O retrocesso observado nacionalmente teve reflexo direto na votação do Plano Municipal de Educação em Petrolina, cidade onde nosso projeto foi aplicado. O Bispo de Petrolina, Dom Manoel dos Reis de Farias, compareceu à sessão na Câmara Plínio Amorim, para expressar sua preocupação com a inclusão das discussões de gênero no Plano Municipal, aprovado em 2015. Ao noticiar a aprovação do Plano, um famoso blog local traz como chamada a frase "Sem ideologia se gênero é aprovado o Plano Municipal na Casa Plínio Amorim", utilizando errônea e tendenciosamente o termo ideologia de gênero. O blog ainda reproduz a fala do Bispo: "Deus criou homem e mulher, então não se pode projeto nenhum ferir aquilo que é direito natural. A educação geral é uma coisa libertadora, mas como eu nunca assisti a uma aula de educação sexual, não tenho como saber, mas dizem que é um 'treinamento sexual'(Brito, 2015).

A construção de projetos proibicionistas ou a retirada da discussão de gênero dos diversos planos estaduais e municipais de educação representam uma grave ameaça ao livre exercício da docência e se opõem, diretamente, às preocupações expressas pelo Ministério da Educação ao pontuar, na Resolução $n^{\circ} 2$, de $1^{\circ}$ de julho de 2015 , a necessidade da presença dos conteúdos relativos a gênero em todos os cursos de licenciatura, tanto na formação inicial quanto na continuada. (Brasil, 2015) 
Compreendemos que os retrocessos, no âmbito legislativo, no que se refere às questões de gênero na educação, já refletem na forma como docentes e alunas/os percebem atividades como as nossas em sala de aula. Por mais que projetos de lei propostos, com base no Escola Sem Partido, tenham sido julgados inconstitucionais e não tenham sido aprovados, as escolas já sofrem influências diretas desses discursos que reverberam no medo que os professores tutores e alunas/os têm de tocar no tema. Para tentar compreender essa nova atmosfera, incluímos, em nosso questionário, perguntas específicas sobre o Escola Sem Partido. Se os Tutores conhecem o projeto, se foram alertados sobre ao longo das atividades ou se isso exerceu sobre eles alguma influência.

Para analisar a experiência, recorremos a metodologias de cunho etnográfico, acompanhamos a aplicação, observamos, anotamos e registramos fotograficamente as atividades. Também gravamos vídeos e realizamos entrevistas. Bem com aplicamos questionários as pibidianas/os e tutores em dois momentos do projeto - logo no início e quando finalizado. A expansão das pesquisas qualitativas na área da educação, nos últimos 30 anos (Andre, 2001), diversificou muito as abordagens, mas sendo as pesquisas em gênero bem mais recentes ${ }^{2}$, muitos estudos se fazem ainda necessários, principalmente na região Nordeste ${ }^{3}$. Adotamos, como referência central, Marli André, em seu estudo Etnografia da Prática Escolar (2009). E apresentamos, aqui, os resultados de uma pesquisa qualitativa, compreendida por nós como a melhor abordagem para captar as vivências dos sujeitos, suas crenças e percepções de mundo, bem como suas representações, intenções e contextos específicos (Bardin, 1977).

Uma questão nos levou a optar pelas oficinas propostas pelo Instituto Sou da Paz e pelo http://generoeeducacao.org.br foi a simplicidade de materiais e métodos. Existe uma fluente confusão entre tecnologia e inovação, em que pese datar da década de noventa, ainda não foi resolvida, visto que muitos recorrem à tecnologia para reinventar o quadro negro. Não propondo, nada que seja, de fato, novo. Acreditando ser a função da escola, sempre, fazer pensar, optamos por uma problematização com textos e vídeos mais demorados e aplicações de materiais, que, embora mais simples, foram

\footnotetext{
${ }^{2}$ Os estudos de gênero na escola têm como referência a professora pesquisadora Guacira Louro, cujas obras datam da década de noventa do século passado. Gênero, sexualidade e educação. Guacira Lopes Louro - Petrópolis, RJ Uma perspectiva pós-estruturalista /: Vozes, 1997.

${ }^{3}$ As pesquisadoras Claudia Vianna e Sandra Humbehaun fizeram levantamentos sistemáticos sobre as pesquisas sobre gênero e educação, realizadas nas décadas de noventa e primeira década do século XIX, no nordeste, destaca-se como o mais antigo grupo de estudos de gênero Núcleo de Estudos Interdisciplinares sobre a Mulher - NEIM, da UFBA, mas poucos são os outros que se destacam nos estudos interdisciplinares e na educação. (UNBEHAUM \& VIANNA, 2006)
} 
profundamente motivadores e envolventes, segundo os resultados que mostraremos a seguir. Antes, ficaremos com a reflexão de Gadotti sobre a escola e as metodologias para o fazer pensar:

Os sistemas educacionais ainda não conseguiram avaliar suficientemente o impacto da comunicação audiovisual e da informática, seja para informar, seja para bitolar ou controlar as mentes. Ainda trabalha-se muito com recursos tradicionais que não têm apelo para as crianças e jovens. Os que defendem a informatização da educação sustentam que é preciso mudar profundamente os métodos de ensino para reservar ao cérebro humano o que lhe é peculiar, a capacidade de pensar, em vez de desenvolver a memória. Para ele, a função da escola será, cada vez mais, a de ensinar a pensar criticamente. Para isso é preciso dominar mais metodologias e linguagens, inclusive a linguagem eletrônica (GADOTTI,2000: 5).

Seguindo na reflexão sobre a educação, recorremos a Gert Biesta (2013). Esse autor nos coloca questões centrais para pensar a partir da linguagem, entre as quais destacamos a preocupação em como repensar a autonomia e reagir responsavelmente a quem é o outro. Para o autor, devemos ter em mente que vivemos num mundo plural, logo a grande preocupação da educação deve ser, não com uma concepção iluminista de humanismo, mas, sim, com a possibilidade de compreender e conviver com o outro. E, principalmente, de ensinar a convivência.

O autor apresenta três conceitos centrais para pensar a educação: confiança, violência transcendental e responsabilidade. O primeiro se refere à necessidade de $\mathrm{o}$ estudante jogar-se dentro de um ambiente-mundo, do qual ele não sabe o que vai receber, no qual pode apreender mais ou menos do que esperava ou até coisas completamente diferentes; o segundo é o conceito de violência transcendental - que está ligado ao ato de ser atingido por uma série de informações e ações externas, sendo a relação aluno-professor um corte na vida do estudante; e, por último, o autor nos apresenta o conceito de responsabilidade. Essa responsabilidade é, segundo ele, incomensurável, pois o professor nunca sabe o alcance que sua influência terá na vida dos alunos e alunas, por isso sua enorme responsabilidade com a educação das/os mesmas/os. Como, então, formarmos licenciadas e licenciados sem noção dessas responsabilidades? Sob essas influências ora apresentadas, construímos o percurso desse projeto, cujos resultados serão apresentados, pensando que, mais do que repassar conteúdos, nossa obrigação enquanto docentes é produzir uma educação libertadora:

A educação libertadora tem, fundamentalmente, como objetivo desenvolver a consciência crítica capaz de perceber os fios que tecem a 
realidade social e superar a ideologia da opressão. Na verdade, esse não é objetivo dos opressores que tentam manter, por meio da educação bancária, a reprodução da consciência ingênua, acrítica. Na educação como prática da liberdade, os homens e as mulheres são vistos como"corpos conscientes", e se tem convicção profunda no poder criador do ser humano como sujeito da história - uma história inacabada, construída a cada instante, cujo processo de conhecer envolve intercomunicação, intersubjetividade. Os protagonistas do processo são os sujeitos da educação - estudante e professor(a) -, que, juntos, dialogam, problematizam e constroem o conhecimento (MENEZES \& SANTIAGO, 2014:50).

\section{RESULTADOS}

A culminância da aplicação das oficinas aconteceu no mês de dezembro em ambas as escolas, coincidindo com as ocupações que aconteceram em todo o território nacional contra a PEC que reduz o teto dos gastos de educação. Muitas das pibidianas/os estavam participando das ocupações, mas mantinham, paralelamente, as atividades do PIBID, levando para as escolas os problemas vivenciados em toda a nação. Esse movimento, ao invés de enfraquecer, foi um incentivo às atividades de culminância do projeto, que saíram das salas de aula e tomaram toda a escola, mobilizadas que foram dentro dessa luta maior.

As oficinas de estêncil tomaram os muros da Escola Otacilio Nunes. A Escola de Aplicação vivenciou oficinas ao ar livre sobre mulheres no futebol e contação de histórias. Todas as atividades propostas pelas alunas/os foram realizadas, foi mantido o cronograma proposto e não tivemos baixa de aluna/o por mau comportamento ou por descumprimento das normas do programa. No Seminário anual do PIBID da instituição, todos os projetos foram apresentados, apenas uma aluna não esteve presente, pois estava doente, tendo sua falta justificada. Todas essas atividades, devidamente acompanhadas e registradas, foram seguidas de um último questionário avaliativo. Nesses questionários, foram trazidas algumas dificuldades e questões que ficaram por abordar e que, esperamos, sejam frutos de um próximo projeto.

Todas as alunas/os apontaram a importância das discussões da temática em sala de aula e o quanto suas concepções sobre gênero e docência foram modificadas. Mesmo sendo a Universidade de Pernambuco uma instituição com sete cursos de licenciatura, não temos disciplinas de gênero de forma obrigatória em nenhum desses cursos. Outra questão importante apontada pelas pibidianas/os foi como as discussões de gênero levantaram outros assuntos, tais como racismo, pobreza, bulling e preconceitos em 
geral, fazendo-nos refletir sobre a importância de trabalhar melhor com eles a perspectiva da Interseccionalidade. Uma questão importante apontada foi a dificuldade, por parte de alguns alunos em participar das discussões no início. Digo alunos, pois registraram que, eles, mais que elas, sentiram dificuldades de se expressarem sobre a temática. Enquanto as meninas se sentiram mais à vontade para falar, alguns alunos também disseram ser proibidos de falar de gênero, em sala de aula, para um dos supervisores.

Os supervisores merecem uma análise à parte. Ao contrário das pibidianas/os, eles, ambos os homens, licenciados em História, não tiveram preparação na graduação para falar sobre gênero na educação, nem em projeto semelhante e nunca tinham trabalhando nem voluntariamente esse tema em sala de aula. O mais velho, de 40 anos, se mostrou mais indiferente à temática, cumprindo o cronograma das atividades com responsabilidade, mas sem muito envolvimento. Sempre que possível, questionava-me sobre a legalidade da discussão do tema em sala. Já o mais novo, 30 anos, também estudante de direito no curso noturno, se envolveu mais energicamente nas atividades, acompanhando diretamente as alunas/os, sendo solícito, fazendo uma ponte com a direção da escola e com as alunos/os de forma geral. Podemos afirmar que, nessa escola, o projeto fluiu muito mais tranquilamente. E tocamos numa questão que para nós é central: a formação das professoras e professores. Aí reside nossa dificuldade, são elas e eles que não têm preparação para tocar no assunto, não alunos e alunas para receber. Por isso, a importância de reforçarmos os cursos de licenciatura, tal qual dita a Resolução de julho de 2015.

\section{CONSIDERAÇÕES FINAIS}

Para nossas considerações finais, optamos por trazer alguns dados recentes para reflexão. O Brasil foi submetido, no último dia 5 de Maio de 2017, à Revisão Periódica Universal-RPU da ONU (Organização das Nações Unidas). Mecanismo estabelecido dentro do Conselho de Direitos Humanos desta organização, essas revisões ocorrem desde 2006 e o Brasil já apresentou seu $3^{\circ}$ relatório sendo sabatinado anteriormente em 2007 e 2012. Entre os pontos que se destacam na RPU de 2017, estão aqueles ligados à violência de gênero e à educação. Os números alarmantes de feminicídio e de violência contra transgênero, travestis e gays foram pontuados por mais de 27 países, para alertar o Brasil sobre a necessidade de campanhas e investimentos em políticas públicas para 
reduzir essa violência alarmante.

Quanto à educação, muitas dessas recomendações estão ligadas a como as políticas de austeridade vão afetar os investimentos na educação brasileira. Destacamos a critica que a Finlândia faz a exclusão das questões relativas à orientação sexual e a gênero da proposta da Base Nacional Comum Curricular, chamando-a de antidemocrática e de espécie de censura. Após a apresentação das considerações sobre os relatórios, um dos representantes da delegação finlandesa falou, especificamente, repudiando o Escola sem Partido, alertando para o perigo que ela representa para uma educação democrática. Lembramos da Finlândia, um dos países que se destaca no mundo no âmbito da educação. Como dissociar as duas questões? Como combater a violência de gênero sem discutir essas questões no âmbito da educação? Nossa proposta foi trazer essa discussão para a sala de aula de duas escolas sob nossa coordenação no PIBID interdisciplinar da UPE, campus Petrolina. Esperamos que muitas outras iniciativas como esta se multipliquem e que possamos fortalecer redes de resistência para uma educação de fato transformadora em nosso País.

\section{REFERÊNCIAS BIBLIOGRÁFICAS}

AGÊNCIA, Brasil. STF suspende lei que instituiu o Programa Escola Livre. Disponível em:<http://agenciabrasil.ebc.com.br/politica/noticia/2017-03/stf-suspendelei-que-instituiu-oprograma-escola-livre-em-alagoas >. Acesso em 21 jun. 2017.

ANDRÉ, Marli. Pesquisa em educação: buscando rigor e qualidade. Cadernos de Pesquisa, n. 113. p.51-64. jul. 2001.

BARDIN, Laurence. Análise de conteúdo. 1977.

BIESTA, Gert. Para além da aprendizagem: educação democrática para um futuro humano. Trad. RosauraEichenberg. Belo Horizonte, MG: Autêntica Editora, 2013.

BRASIL, Constituição. Constituição da República Federativa do Brasil. Brasília, DF: Imprensa Oficial, 1988.

Ministério da Educação. Resolução $\mathbf{n}^{\mathbf{0}}$ 2, de 1 de julho de 2015, defini as Diretrizes Curriculares Nacionais para a formação inicial em nível superior (cursos de licenciatura, cursos de formação pedagógica para graduados e cursos de segunda licenciatura) e para a formação continuada. Conselho Nacional de Educação: Conselho Pleno, 2015a. Disponível em:<www.ead.unb.br/index.php/todas.../140-resolucao-n-2de-1-de-julho-de-2015-cne> cesso em: 13 set. 2016.

Plano Nacional de Educação (PNE). Plano Nacional de Educação 2014-2024:

Lei $\mathrm{n}^{\circ}$ 13.005, de 25 de junho de 2014, que aprova o Plano Nacional de Educação 
(PNE) e dá outras providências. 2ed. Brasília: Câmara dos Deputados, Edições Câmara, 2015b. Série Legislação n. 193.1 Disponível em: <bd.camara.gov.br/bd/.../bdcamara/.../plano_nacional_educacao_2014-2024_2ed.pdf>. Acesso em: 10 set. 2016.

Presidência da República. Secretaria Especial de Políticas para as Mulheres. Plano Nacional de Políticas para as Mulheres. Brasília: Secretaria Especial de Políticas para as Mulheres,2004. Ministério da Educação. Programa Mulher e Ciência. Prêmio Construindo a Igualdade de Gênero. 2016a. Disponível em: <http://www.igualdadedegenero.cnpq.br/igualdade.html>. Acesso em: 20 ago. 2016.

Presidência da República. Medida Provisória no 726, de 12 de maio de 2016, altera e revoga dispositivos da Lei no 10.683, de 28 de maio de 2003, que dispõe sobre a organização da Presidência da República e dos Ministérios. Brasília: Casa Civil, 2016e. Disponível em: <http://www.planalto.gov.br/ccivil_03/_Ato2015018/2016/Mpv/mpv726.htm>. Acesso em 15 set. 2016.

Ministério do Planejamento. Retrato das Desigualdades de Gênero e Raça. Instituto de Pesquisa Econômica Aplicada. 2016b. Disponível em: <http://www.ipea.gov.br/retrato/apresentacao.html>. Acesso em 10 set. 2016.

Secretaria de Educação Fundamental. Parâmetros curriculares nacionais: orientação sexual. Brasília: MEC/SEF, 1998.

Senado Federal. Projeto de Lei do Senado, de 2016, que inclui as diretrizes e bases da educação nacional, de que trata a Lei $\mathbf{n}^{\circ} \mathbf{9 . 3 9 4}$, de 20 de dezembro de 1996, o "Programa Escola Sem Partido". Brasília: Congresso Nacional, 2016f. Disponível em: <https://www12.senado.leg.br/ecidadania/visualizacaomateria?id=125666>. Acesso em: 19 set. 2016.

Portal da Transparência. Convênio 603408. Fundo Nacional de Desenvolvimento da Educação. 2016c. Disponível em: $<$ http://www.portaltransparencia.gov.br/convenios/DetalhaConvenio.asp?TipoConsulta $=5 \&$ CodConvenio $=603408>$. Acesso em: 21 set. 2016 .

BORTOLINI, Alexandre. Diversidade sexual e de gênero na escola. Revista Espaço Acadêmico. N. 123. Ago. 2011.

BRITTO, Carlos. Sem 'ideologia de gênero', Plano Municipal de Educação é aprovado pela Casa Plínio Amorim. Blog do Carlos Britto. Petrolina, 23 jun. 2015. Disponível em: <http://carlosbritto.ne10.uol.com.br/sem-ideologia-de-genero-plano-municipal-deeducacaoeaprovado-pela-casa-plinio-amorim/> . Acesso em: 21 set. 2016.

FREIRE, Paulo. Pedagogia da autonomia: saberes necessários à prática educativa. 43 . ed., São Paulo: Paz e Terra, 1996.

FOUCAULT, Michel. História da sexualidade I: a vontade de saber. Rio de Janeiro: Edições Graal, 1988. 
GADOTTI, MOACIR. Perspectivas atuais da educação. São Paulo Perspec. [online]. 2000, vol.14, n.2, pp.03-11.

HOOKS, Bell. Ensinando a transgredir: a educação como prática da liberdade. São Paulo: Editora WMF Martins Fontes, 2013.

LOURO, Guacira L. Gênero, sexualidade e educação: uma perspectiva pósestruturalista. 16 ed. Petropólis, RJ: Vozes, 2014.

MENEZES, Marília Gabrielle; SANTIAGO, Maria Eliete. Contribuição do pensamento de Paulo Freire para o paradigma curricular crítico-emancipatório. Pro-Posições| v. 25, n. 3 (75)| P. 45-62, set./dez. 2014.

MINAYO, Maria Cecília. O desafio do conhecimento pesquisa qualitativa em saúde. Editora Hutec, São Paulo. 2004.

MINISTÉRIO DA EDUCAÇÃO. Conselho Nacional de Educação. Nota pública, Às Assembleias Legislativas, à Câmara Legislativa do Distrito Federal, às Câmaras de Vereadores, aos Conselhos Estaduais, Distrital e Municipais de Educação e à Sociedade Brasileira. Brasília: 1 set. 2015. Disponível em: <http://www.spm.gov.br/noticias/conselhonacional-de-educacao-emite-notasobreideologia-de-generonosplanosdeducacao/nota publica_sobre_ideologia_genero_01_09-1.pdf>. Acesso em: 20 set. 2016.

MORIN, Edgar. Os sete saberes necessários à educação do futuro. $5^{\mathrm{a}}$ ed. São Paulo, Brasília DF: Cortez / UNESCO, 2002.

ONU, Mulheres. Gênero na Escola e na Universidade. 13 abr. 2016. Disponível em: <http://www.onumulheres.org.br/programasemdestaque/genero-na-escola/>. Acesso em 15 jun. 2017.

RAGO, Margareth. As mulheres na historiografia brasileira. In: SILVA, Zélia L. (Org.). Cultura Histórica em Debate. São Paulo: UNESP, 1995.

Epistemologia feminista, gênero e história. In: PEDRO, Joana; GROSSI, Miriam. (Org.).Masculino, Feminino, Plural. Florianópolis: Editora Mulheres, 1998. p. 1-17.

SAVIANI, D. Escola e democracia. 24. ed. São Paulo: Cortez, 1991.

SCOTT, Joan. Experiência. In: SILVA, Alcione L.; LAGO, Maria C. de S.; RAMOS, Tânia R. O. Falas de gênero: teorias, análises, leituras. Florianópolis: Editora Mulheres, 1999. p.21-55.

Gênero: uma categoria útil de análise histórica. Educação \& Realidade, Porto Alegre, v.20, n. 2, p. 71-99, jul./dez. 1995. dez. 2012 .

Os usos e abusos do gênero. Projeto História, São Paulo, n. 45, p. 327-351, TIBURI, Márcia. Como conversar com um fascista. Rio de Janeiro: Record, 2016. 
UNESCO. UNESCO no Brasil se posiciona sobre questões de violência de gênero. Disponível em: <http://www.unesco.org/new/pt/brasilia/about-thisoffice/singleview/news/unesco_in_brazil_stands_against_gender_violence_issues/\#.V2 LkNrsrKUn>. Acesso em 10 jun. 2017.

VIANNA, Cláudia Pereira. Estudos sobre gênero, sexualidade e políticas públicas: das ações coletivas aos planos e programas federais. São Paulo. Tese de livre docência. 2011.

VIANNA, Cláudia; UNBEHAUM, Sandra. Gênero na Educação Básica: quem se importa? Uma análise de documentos de políticas públicas no Brasil. Educação \& Sociedade, Campinas, v. 27, n. 95, p. 407-428, maio/ago. 2006. 